\title{
O Desenvolvimento de Objetos de Aprendizagem no Museu Zoobotânico Augusto Ruschi ${ }^{*}$
}

\author{
Ana Carolina Bertoletti-De-Marchi ${ }^{* *}$ \\ Flávia Biondo da Silva ${ }^{* * *}$
}

Resumo: Este artigo tem como objetivo apresentar o processo de desenvolvimento de objetos de aprendizagem no Museu Zoobotânico Augusto Ruschi (Muzar). Os museus estão entre os espaços educacionais que contribuem para o crescimento de novas fontes eletrônicas de informações voltadas para a aprendizagem. De modo a disponibilizar tais informações ao público em geral, estão sendo desenvolvidos no Muzar objetos de aprendizagem na forma de multimídias e jogos educativos. Além de informativos e práticos, as multimídias e os jogos devem desenvolver o senso crítico, serem contextualizados e oferecer o máximo de interação ao visitante. As multimídias são contextualizadas com temas e demais atividades que o Muzar desenvolve. Os objetos de aprendizagem desenvolvidos nesta pesquisa serão depositados em um repositório, onde será permitida a consulta bilateral dos mesmos. Este ambiente está sendo desenvolvido em uma outra pesquisa complementar.

Palavras-chaves: objetos de aprendizagem, multimídia, jogos educativos e aprendizagem em museus.

The Development of Learning Objects in the Zoobotânico Augusto Ruschi Museum Abstract: This paper intends to present the process of development of leraning objects in the Zoobotânico Augusto Ruschi Museum (Muzar). The museums are among the educational spaces that contribute to the growth of new electronic sources of learning information. In way to offer such information to the general public, are being developpment in Muzar learning objects such as multimedia and education games. Beyond the informational and practice, multimedias and games must develop the critical sense, to be inside of a context and to offer the maximum of interaction to the visitor. The multimedias offer subjects and too much activities that the Muzar develops. The learning objects development in this research will be deposited in a repository, where to be permitted the bilateral search of the same ones. This environment is being developed in another complementary research.

Keywords: learning objects, multimedia, education games and learning in museums.

\section{Introdução}

O Museu Zoobotânico Augusto Ruschi (Muzar) é um setor de apoio e extensão do Instituto de Ciências Biológicas (ICB) da Universidade de Passo Fundo (UPF)/RS, que completou vinte e nove anos no dia 25 de agosto de 2004.

Em seus quase trinta anos apresenta um caminho diversificado de envolvimento com a comunidade, buscando atualmente participar efetivamente do processo educacional da universidade, da escola e da vida.

\footnotetext{
"Artigo elaborado a partir do projeto de pesquisa Muzar Incorporando novas tecnologias, com o apoio da FAPERGS através do edital Promuseu e da UPF e como parte integrante da proposta de tese de doutorado no PGIE.

Professora, doutoranda em Informática na Educação (PGIE/UFRGS), professora e pesquisadora da UPF, carolina@upf.br. http://vitoria.upf.br/ carolina

"*** Coordenadora do MUZAR e mestranda em Educação da Universidade de Passo Fundo, biondo@upf.tche.br. V.2 $\mathrm{N}^{\circ} 2$, Novembro, 2004
} 
Os museus na sua maioria surgem de coleções, que são reflexos da personalidade do colecionador. A coleção surge da espontaneidade de quem coleta, conserva, guarda e estuda. Foi assim que surgiu o Muzar, a partir de coleções foi idealizado e várias pessoas, alunos e professores, do curso de Ciências depois de Ciências Biológicas, colaboraram para sua efetivação.

O Muzar desenvolveu-se carregado de desafios, com passos firmes e conscientes. Juntamente com o auxílio do edital de apoio para Museus do Programa de Apoio a Qualificação dos Museus do Rio Grande do Sul (Promuseu/Fapergs), de 2001, o Muzar partiu para tornar o seu acervo interativo, através do uso da informática educativa no contato com seu público.

Os museus, de um modo geral, criam e mantém uma variedade muito rica de informações descritivas para suportar uma grande gama de atividades que abrangem salvaguarda, exposições, educação, programas públicos e pesquisa. Essas informações geralmente são armazenadas usando software próprio para cada departamento das instituições e, muitos deles, não são acessíveis ao público.

Neste contexto, o Muzar começou a desenvolver objetos de aprendizagem (OAs) que pudessem ser utilizados dentro e fora do ambiente do museu, por professores, alunos e público em geral. Deste modo, definimos objetos de aprendizagem baseados no conceito da LTSC (2002) onde são vistos como "qualquer entidade, digital ou não digital, que pode ser utilizada, reutilizada ou referenciada durante o aprendizado apoiado sobre a tecnologia".

Segundo Trant et al. (2002), essa nova diversidade de fontes eletrônicas obtidas com o uso de objetos de aprendizagem oferece muitas vantagens aos museus, como: a freqüente atualização, a possibilidade de suportar múltiplos usuários, o acesso sem considerar as horas em que está aberto, a oportunidade de aperfeiçoamento por parte dos leitores e o acesso a informações por pesquisadores. Além de ampliar a forma comunicativa, o Muzar aumenta as chances de integrar-se com a comunidade e trabalhar pela valorização e preservação do patrimônio natural.

Neste sentido, este artigo irá abordar o processo de criação e desenvolvimento dos objetos de aprendizagem do Muzar, buscando enfatizar a importância da utilização dos mesmos para apoiar a aprendizagem informal.

\section{Objetos de Aprendizagem}

Alguns autores criticam a definição atribuída pelo LTSC (2002), como sendo muito ampla. Para Wiley (2000), os OAs são componentes que podem ser reusados em diferentes contextos de aprendizagem. São geralmente entendidos como entidades digitais que podem ser distribuídas através da Internet, significando que qualquer número de pessoas pode acessá-los e usá-los simultaneamente. O autor salienta a vantagem dos objetos de aprendizagem com relação aos materiais didáticos tradicionais (fitas e vídeos), considerando a fácil distribuição e a reutilização.

Além desta, os OAs apresentam enumeras outras vantagens quanto ao seu uso, que podem ser apontadas considerando quatro pontos de vistas diferentes: do desenvolverdor, tecnológico, do formador e do aprendiz (Bertoletti-De-Marchi 2004).

Do ponto de vista do desenvolvedor, o tempo de desenvolvimento irá reduzir e consequientemente o custo, uma vez que os objetos podem ser reutilizados com outros propósitos. Isso acaba facilitando a distribuição. Do ponto de vista tecnológico salientamos a maior eficiência dos navegadores e da velocidade do trafego de informações quando considerando pequenas quantidades de informações. Do ponto de vista do formador, haverá um acréscimo muito grande na facilidade de adaptar novos cursos e currículos, uma vez que cada objeto é visto como uma pequena unidade de um todo. Por fim, do ponto de vista do aprendiz, os OAs, por apresentarem um tamanho 
reduzido, encorajam a aprendizagem e o estudo, facilitando o gerenciamento do conhecimento. permitirem:

Segundo o site (http://adlcolab.uwsa.edu/lo/), os OAs são criados por

- modularidade: acrescentando versatilidade e funcionalidade;

- benefícios à comunidade: aumentando o conteúdo disponível através de ambientes de suporte a comunidade;

- benefícios institucionais: combinando esforços e compartilhando resultados;

- compartilhamento e reusabilidade: mais retorno para o investimento aplicado no desenvolvimento; e

- uso do material em vários contextos diferentes, reusabilidade.

A estrutura básica de um OA pode ser dividida em duas partes: o conteúdo do objeto (recurso) e o metadado que o explica, também denominado de metadado descritor, como ilustra a figura 1 .

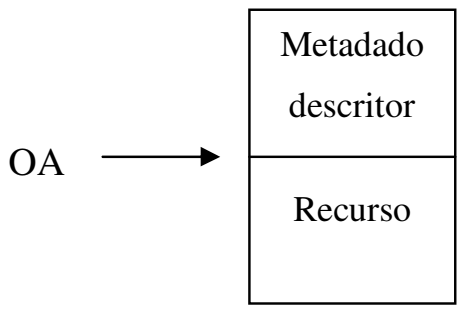

Figura 1 - Estrutura básica de um Objeto de Aprendizagem

Podemos comparar essa estrutura com o esquema de organização de uma biblioteca, onde o livro propriamente dito seria o recurso e a ficha que permite sua localização através de palavras-chave, autor, etc., funcionaria com o metadado descritor.

Os OAs são melhores aproveitados quando organizados em um padrão de metadados, utilizado para recuperar, reusar e combinar diferentes objetos, promovendo também a interoperabilidade. Alguns dos padrões mais importantes desenvolvidos ao redor do mundo são: o LTSC, o ARIADNE e o IMS. A idéia é que o conteúdo deve ser estruturado de forma que cada "módulo" seja uma unidade independente, que é definida através do padrão de metadados. Isto abre a possibilidade de misturar diferentes unidades de aprendizagem e colocá-las juntas para novas finalidades e em novos caminhos de aprendizagem [Olsem, 2002].

Adicionalmente, para possibilitar o armazenamento e o desenvolvimento dos OAs, existem os repositórios de objetos de aprendizagem. Alguns exemplos de repositórios são: CLOE (Cooperative Learnware Object Exchange) desenvolvido na Universidade de Waterloo no Canadá; o MERLOT (Multimedia Educational Repository for Learning and On-Line Teaching) que hoje é o de maior acesso e que teve inicio nas universidades do Estado da Califórnia; o CAREO (Campus Alberta Repository of Educational Objects), entre outros.

Os repositórios funcionam com o uso de um sistema de gerência de objetos de aprendizagem, responsável por manter o recurso e que é semelhante a um SGBD (Sistema de Gerência de Banco de Dados). O objetivo desses sistemas é gerenciar o acesso e a correta manutenção dos dados que serão manipulados, disponibilizando ferramentas para armazenamento, gerenciamento, indexação e estruturação de objetos de aprendizagem armazenados no repositório.

Cabe ressaltar que o ambiente que proporcionará a busca dos objetos de aprendizagem descritos neste artigo está sendo desenvolvido por Bertoletti-De-Marchi V. $2 \mathrm{~N}^{\circ}$ 2, Novembro, 2004 
(2004) através de sua proposta de tese e com apoio do CNPq. Deste modo, não será abordado aqui como será realizada a busca dos OAs que estão sendo desenvolvidos pelo Muzar e que farão parte do repositório utilizado no ambiente. Maiores informações também podem ser encontradas em (Bertoletti-De-Marchi e Costa 2004).

\subsection{Tipos de Objetos de Aprendizagem}

O OA pode conter um simples elemento de comunicação, como vídeo ou texto, ou pode conter uma combinação como texto com gráfico ou animação com comentário em áudio.

O OA pode servir para várias propostas. O que realmente importa é que o objeto seja suficientemente pequeno para ser possível aplicá-lo a uma variedade de situações. A tabela abaixo ilustra alguns tipos de OA.

\begin{tabular}{|c|c|c|}
\hline Integrados & Informativos & Práticos \\
\hline $\begin{array}{l}\text { Mini-tutoriais } \\
\text { Mini estudos de caso, } \\
\text { simulações, etc. com } \\
\text { suporte informativo }\end{array}$ & $\begin{array}{l}\text { Descrições / Definições } \\
\text { Demonstrações / Modelos } \\
\text { Exemplos de trabalhos } \\
\text { Casos / histórias } \\
\text { Artigos }\end{array}$ & $\begin{array}{l}\text { Problemas / Estudos de } \\
\text { Caso } \\
\text { Jogos / Simulações } \\
\text { Exercícios de treinamento e } \\
\text { prática } \\
\text { Exercícios de revisão } \\
\text { Testes / Avaliações }\end{array}$ \\
\hline
\end{tabular}

*Fonte: Shepherd (2000).

Adicionalmente, considerando que este trabalho está voltado para a aprendizagem em museus, podemos apontar como exemplos de objetos de aprendizagem: multimídias, relatórios técnicos, publicações, experimentos e peças de acervo, digitais ou não-digitais.

Segundo Bertoletti-De-Marchi (2004), os museus têm adotado abordagens baseadas em coleções no desenvolvimento de OA, usando itens individuais da história de suas coleções como âncora para projetos de experiências on-line, a fim de engajar estudantes na exploração de temas chave. Cada OA é projetado para ser uma experiência sozinha, mas também podem ser organizados em uma seqüência de muitos objetos refletindo diferentes pontos de vista.

Mais especificamente no contexto deste artigo, nos preocupamos em descrever o desenvolvimento dos OAs do tipo informativos, as multimídias, e práticos, os jogos educativos.

\section{Processo de Desenvolvimento dos Objetos de Aprendizagem do Muzar}

Através do Programa de Apoio a Qualificação dos Museus do Rio Grande do Sul (Promuseu/Fapergs), o Muzar tornou seu acervo interativo, informatizando suas coleções e usando a informática educativa no contato com seu público.

A informática educativa proporciona, através do computador, a interação dos visitantes com os objetos de aprendizagem desenvolvidos sobre os temas que envolvem as ciências ambientais e biológicas, fundamentação do trabalho realizado pelo Museu.

Segundo Silva et al (2004), a criação dos objetos proporcionou um trabalho de relações e interações importantes entre as áreas de ciências da computação e ciências biológicas, as quais apoiaram suas atividades construindo e desconstruindo relações para chegar ao resultado esperado.

Os OAs estão sendo desenvolvidos para promover a interação dos visitantes com as exposições do Muzar, apresentando e discutindo temas ambientais e de curiosidades da área biológica. A informática educativa é utilizada para transmitir conhecimentos de 
forma didática e criativa, e para sensibilização, para que o visitante reflita sobre as informações que recebe, mas também, oportuniza a participação do visitante para dar opinião e criar informações.

Estamos inicialmente desenvolvendo OAs do tipo multimídias e jogos educativos. Segundo Chaves (1991), "o termo multimídia se refere à apresentação ou recuperação de informações que se faz, com o auxílio do computador, de maneira multisensorial, integrada, intuitiva e interativa". Nos museus, as multimídias têm a função de registrar uma área especifica da exposição, objetos ou coleções. Na criação de novas exibições, utiliza-se a multimídia para a apresentação das informações, tornandoas mais atrativas ao público.

Para iniciar o processo de desenvolvimento, a coordenação e orientação do projeto desenvolveram uma ambientação através da educação ambiental e o reconhecimento dos princípios que fundamentam o Muzar. Após, o trabalho técnico fluiu necessitando sempre da orientação referente ao objetivo educativo que o recurso de aprendizagem precisava manter.

Assim sendo, para o desenvolvimento dos OAs, foi feito o reconhecimento dos princípios de educação ambiental que regem o Muzar, identificando os objetivos e finalidades pelos quais o Museu Zoobotânico existe. Através do estudo das atividades e temas que o Muzar desenvolve foi feito o delineamento da página virtual, onde os objetos estão disponíveis para consulta até que o ambiente de consulta ao repositório seja finalizado com a especificação do metadado descritor de cada objeto.

Fez-se à investigação das informações científicas dos temas e assuntos para serem desenvolvidos nas multimídias e jogos educativos, a digitalização das fotos e figuras para ilustração, complementado com o registro fotográfico do acervo, de animais, de vegetais, bem como paisagens, pessoas e objetos necessários, para a implementação da proposta. Adequou-se das informações científicas de forma didaticamente compreensíveis, sintetizando quanto a importância e a quantidade de informações, adaptando os recursos para que tenham todas as características de OAs.

Além de informativas e práticas, as multimídias e os jogos educativos devem desenvolver o senso crítico, serem contextualizados e oferecer o máximo de interação ao visitante. Os OAs são contextualizados com temas e demais atividades que o Muzar desenvolve, como exemplo:

- a Festa dos Artrópodes: que apresenta o cotidiano do museu, através de uma história onde esclarece a importância desses animais na natureza e quais os prejuízos que eles podem causar ao ser humano, quando considerados peçonhentos;

- o jogo das Plantas Medicinais: o visitante relaciona seu conhecimento com a imagem, o nome comum e o uso farmacológico;

- a multimídia Curiosidades da Natureza: que responde as perguntas mais comuns feitas pelos visitantes do Muzar.

- as multimídias Arborização, Lixo, Água e Saneamento Básico: são informativas, servem como pesquisa bibliográfica para ensino fundamental e médio, pois agregam conceitos e normas técnicas de maneira clara e atrativa.

Conforme Silva et al (2004), o Muzar recebe alunos, das escolas da região norte do Rio Grande do Sul, de todas as idades e níveis de ensino e as multimídias e diversões educativas são adequadas aos visitantes. As diversões interativas são a atração das crianças que aprendem brincando e relacionando, como se observa durante as visitações.

Nas diversões interativas eles reconhecem o mascote "Formiguito" do Muzar, trabalham os animais ameaçados de extinção através do Jogo da Memória e do Pintando V. $2 \mathrm{~N}^{\circ}$ 2, Novembro, 2004 
os Bichos. No Jogo da Forca relacionam as respostas com a Exposição de Longa Duração do museu e no Separando o Lixo e no Jogo do Rio relacionam com o dia-a-dia sobre a coleta seletiva e os rios de suas cidades. As figuras 2, 3 e 4 ilustram alguns exemplos de multimídia e jogos educativos desenvolvidos.

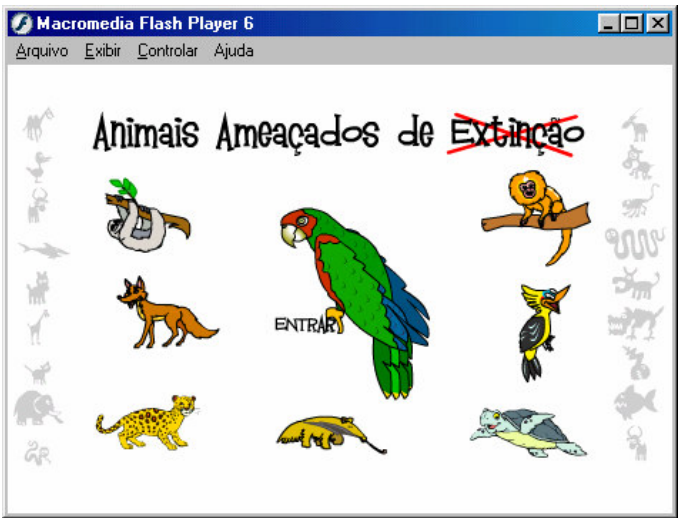

Figura 2 - Exemplo de Multimídia

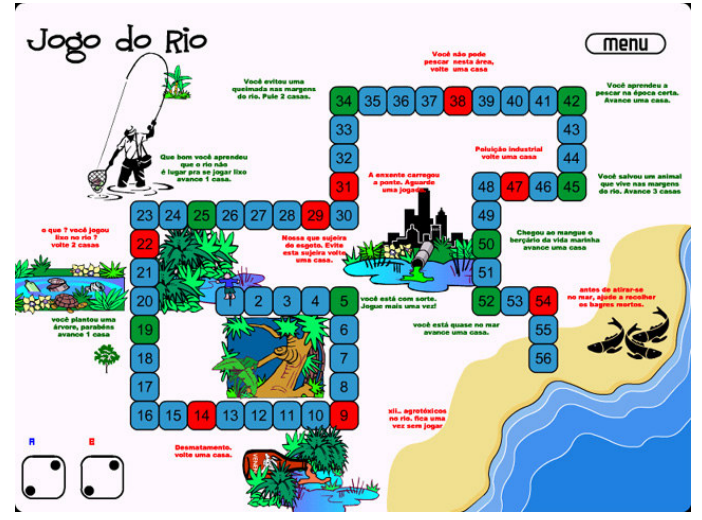

Figura 3 - Exemplo de Jogo Educativo

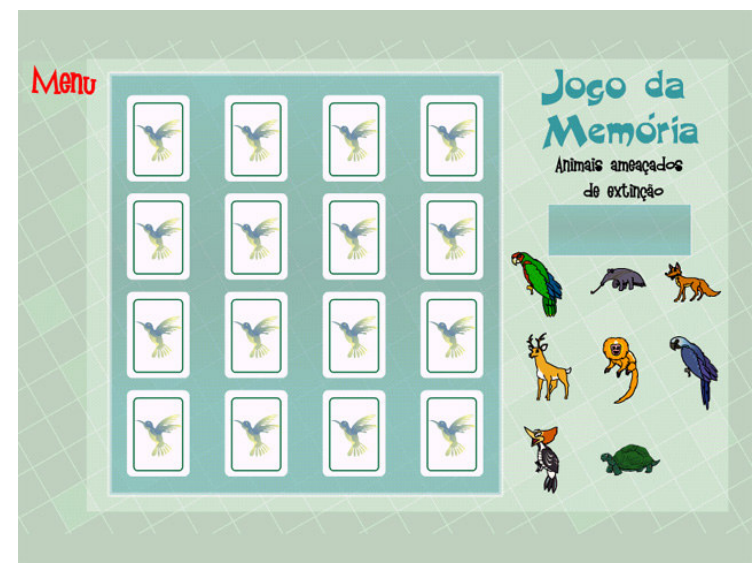

Figura 4 - Exemplo do Jogo de Memória

Os OAs estão disponíveis aos visitantes, através de computadores distribuídos no espaço físico das exposições dando acesso para aproximadamente dez mil pessoas que anualmente visitam o museu, oportunidade de contribuir com escolas que ainda não possuem o computador, mas que visitam o Museu Zoobotânico Augusto Ruschi. Em breve todos os OAs poderão ser consultados através do ambiente de consulta bilateral que está sendo proposto por Bertoletti-De-Marchi (2004).

Cabe ressaltar que os OAs citados acima foram todos desenvolvidos utilizando a tecnologia HTML e FLASH com os respectivos programas, Macromedia Dreamweaver e Macromedia Flash.

\subsection{A Importância dos OAs para instrumentalizar às ações educativas do Muzar}

Segundo Oliveira (2001, p.73 e 77), a informática e o desenvolvimento da Internet estão trazendo para a área museológica significativas transformações, mas que diante do quadro "globalizante" a informatização é um instrumento de trabalho que auxilia na fundamentação do papel dos "novos" museus, de salvaguardar e comunicar os valores tradicionais e comunicá-los como elementos sociais dinâmicos e vivos, base de identidades cullturais. 
Giraudy \& Bouilhet (1990, p. 11-13) ressaltam que mitos são freqüentemente criados assimilando as visitas aos museus como uma obrigação cultural tediosa, em que as exposições são cuidadosamente resguardadas, indiscutíveis, com identificações pouco legíveis, não contextualizadas e seguidas dos rotineiros proibidos tocar, fotografar, rir, comer, correr, falar alto, característico dos museus tradicionais, elitistas, com visão de cultura européia.

De acordo com Santos (1993, p. 73) os museus hoje não podem se mover no interior de uma estrutura rígida, mas pelo contrário, precisam contar com elementos dinâmicos e flexíveis que lhes permitam adaptarem-se às constantes mudanças, possuindo objetivos e funções claras e postura crítica diante da realidade.

Foi através de um processo que a nova museologia foi concebida, e em 1972 através, na Mesa-Redonda de Santiago do Chile, promovida pelo ICOM (Conselho Internacional de Museologia) foi fundamentado o museu como uma instituição a serviço da sociedade, da qual é parte integrante e que possui em si próprio os elementos que lhe permitem participar na formação da consciência das comunidades a que serve.

Conforme Santos (2002, p. 108-109), um dos princípios básicos que norteiam as ações da nova museologia é a interpretação da relação entre o ser humano e o meio ambiente e da influência da herança cultural e natural nas identidades dos indivíduos e dos grupos sociais, e que sua proposta básica está pautada no diálogo, no argumento em contextos interativos, o espaço social onde será realizada a razão comunicativa.

Fundamentado na nova museologia e respaldado na educação ambiental, vertentes da mesma época e de princípios semelhantes, o Muzar busca, através do desenvolvimento de OAs interagir com seu público, dando oportunidade a sociedade ter acesso as pesquisas desenvolvidas.

Segundo Bertoletti-De-Marchi (2004), para apoiar a aprendizagem informal em museus, os OAs podem ser utilizados das mais diversas formas, considerando um público bastante diversificado em contextos distintos. A autora inicia a análise de propostas de uso de $\mathrm{OA}$ em museus pensando nas distinções com relação ao público alvo, onde diferenciamos o visitante on-line do visitante do museu físico. Chadwick (1999), em seus estudos sobre as diferenças entre os visitantes, concluiu que todos os usuários buscam em um site de museu (http://www.upf.br/muzar) um ambiente informal de aprendizagem, isto é, um recurso extra de aprendizado, principalmente os grupos, pois procuram o site para pesquisar e aprender.

De acordo com o contexto acima, os OAs podem ser utilizados por ambos visitantes para: realizar uma pesquisa; aprofundar conhecimentos; ser utilizado na construção de um curso; servir como material de apoio; entre outros.

Vários museus ao redor do mundo estão adotando os OAs em sua realidade. No The National Museum of Australia os OAs são utilizados para o desenvolvimento de multimídias educacionais on-line para uso em sala de aula utilizando os recursos e coleções do museu. Essa representação digital das coleções acarreta mudanças na representação dos objetos pertencentes às mesmas para uso no espaço interativo on-line. Essas mudanças estão sendo estudadas por Payne e Peacock (2004).

Observa-se que o uso de $\mathrm{OA}$ em museus é muito amplo e atinge os mais diversos públicos, desde o público em geral, até alunos e professores do sistema formal.

No momento em que os museus construírem um repositório de OA, os mesmos estarão ampliando sua missão com o público, oferecendo mais um serviço pronto a auxiliar na construção do conhecimento, seja no ensino formal, não-formal ou informal.

Devemos aproveitar todo o conhecimento que é gerado pelas equipes de museus, não o deixando restrito ao mundo museal.

\section{Conclusões}


O Museu Zoobotânico Augusto Ruschi (Muzar) ao aplicar o projeto "O Muzar Incorporando Novas Tecnologias", incorpora mais um instrumento de comunicação para alcançar seu público, trabalhando para desmistificar conceitos museológicos, criados pela sociedade, que distancia as pessoas da cultura, e abre espaço de interação do conhecimento científico com o visitante e pesquisador, diminuindo o problema da distância e do tempo, possibilitado pela internet.

Para os museus, além de comunicadora, a informática é um canal de pesquisa disponibilizando maior e melhor acesso aos recursos disponíveis. $\mathrm{O}$ acesso via internet diminui consideravelmente o tempo investido para a consulta de dados.

A mudança na linguagem museográfica modifica a rotina do Muzar, apreendendo por mais tempo o visitante, possibilitando relações das exposições com as multimídias, jogos e a pesquisa de temas freqüentes nas escolas.

As multimídias, como uma das opções interativas do Muzar, estão colaborando na ampliação do número de visitantes e efetivando o museu no processo educacional das escolas.

O Muzar terá condições de transmitir as informações restritas ao mundo científico, para uma comunidade sedenta de informações sobre o Patrimônio Natural da região e sensibilizado para agir pela sua preservação.

Com o auxilio da informática o Muzar pretende contribuir na desmistificação da visão tradicional de museu e promover a sensibilização e conscientização da sociedade na valorização das culturas tradicionais, preservação dos recursos naturais e na troca e disseminação de conhecimento.

\section{Agradecimentos}

Agradecemos a Fundação de Amparo a Pesquisa do Rio Grande do Sul (FAPERGS) pela oportunidade de realizar esse projeto apoiado pelo edital Promuseu e ao Conselho Nacional de Desenvolvimento Científico e Tecnológico - CNPq - pela aprovação do projeto de irá complementar esta proposta, através do edital $\mathrm{MCT} / \mathrm{SECIS} / \mathrm{CNPq} \mathrm{n}^{0}$ 07/2003. Adicionalmente, agradecemos aos acadêmicos da Universidade de Passo Fundo que participaram do projeto, bem como, funcionários, estagiários e professores do Museu Zoobotânico Augusto Ruschi e as direções dos Institutos de Ciências Biológicas e Ciências Exatas e Geociências pelo apoio.

\section{Referências Bibliográficas}

BERTOLETTI-DE-MARCHI, A. C. A Informática apoiando o processo de ensinoaprendizagem de museus de ciências e tecnologia (Título provisório). Proposta de tese a ser defendida. Porto Alegre: PGIE, 2004.

BERTOLETTI-DE-MARCHI, A. C. e COSTA, A.C.da R. Uma proposta de padrão de metadados para objetos de aprendizagem de Museus de Ciências e Tecnologia. RENOTE - Revista Novas Tecnologia na Educação. POA/UFRGS, v.2,n.1,2004.

CHADWICK, J. A. Survey of Characteristics and Patterns of Behavior in Visitors to a Museum WebSite. In: D. Bearman and J. Trant (Eds.) Museums and the Web 99. Archives and Museum Informatics, 1999. USA: New Orleans. P. 154-162.

CHAVES, E. O. C. Multimídia: conceituação, aplicações e tecnologia. São Paulo, 1991.

GIRAUDY, Danièle; BOUILHET, Henri. O museu e a vida. Trad. Jeanne France Filiatre Ferreira da Silva. Rio de Janeiro: Fundação Nacional Pró-memória; Porto Alegre: Instituto Estadual do Livro --RS; Belo Horizonte: UFMG, 1990.

ICOM. Mesa-redonda de Santiago do Chile. 1972. Revista Museu: cultura levada a sério. Disponível em <http://www.revistamuseu.com.br/legislação/museologia /mesa-chile.htm>. Acesso em 13 out. 2003. 
IEEE Learning Technology Standards Committee (LTSC) (2002) "Draft Standard for Learning Object Metadata IEEE 1484. http://ltsc.ieee.org/

OLIVEIRA, João Batista Gomes de. Museu, museologia e patrimônio cultural: subsídios para implantação de instituições museológicas. Macapá: UNIFAP/FUNDAP, 2001.

PAYNE, M. e Peacock, D.. Collection Object to Learning Object. In: D. Bearman and J. Trant (Eds.) Museums and the Web 04. Archives and Museum Informatics, 2004. USA.

SANTOS, Maria Célia Teixeira Moura. Reflexões museológicas: caminhos de vida. Cadernos de Sociomuseologia. Centro de Estudos de Sociomuseologia. Lisboa: ULHT, n. 18, 187 p. 2002.

Repensando a ação cultural e educativa dos museus. 2.ed. ampl.. Salvador: Centro Editorial e Didático da UFBA, 1993.

SILVA, Flávia Biondo da et al. O software educativo do Museu Zoobotânico Augusto Ruschi, SIMPÓSIO GAÚCHO DE EDUCAÇÃO AMBIENTAL, 3, 2004, Erechim. Trabalho apresentado...Erechim: URI, 2004. CD-ROM.

SHEPHERD, C. Objects of interest. (2000) Disponível por: http://www.fastrakconsulting.com.uk/tactix/features/objects/objects.htm. Recuperado em: 01/09/2004.

TRANT, J.; BEARMAN, D.. 2002. Educational Use of Museum Multimedia the AMICO Library. Art Libraries Journal, Volume 27, No. 2.

WILEY, D.. Connecting learning objects to instructional design theory: A definition, a metaphor, and a taxonomy. In: The Instructional Use of Learinng Object - On-line Version. 2000. Disponível por: http://reusability.org/read/. Acessado em: 02/09/2004. 